\title{
$>$ Três contos de morte de Horacio Quiroga
}

> Three tales of death by Horacio Quiroga

tradução de Juan Carlos Acosta

Mestrando em Letras na área de Lexicografia, Terminologia e Tradução da Universidade Federal do Rio Grande do Sul (UFRGS). E-mail: juannacosta82@gmail.com. ORCID: 00000003-3567-0971. 


\section{Introdução}

Os três contos aqui reunidos foram originalmente publicados em 1917 no livro Cuentos de Amor De Locura y de Muerte. Silvina Caeiro ${ }^{1}$ comenta que "o autor mantém uma unidade narrativa relacionando os três temas que dão nome ao livro". Quiroga é um escritor capaz de conseguir, com a brevidade de seus relatos, a plena atenção do leitor, e o mantém nessa tensão até chegar no final (sem final, em alguns casos).

Nestes contos aqui selecionados, nota-se claramente a influência de Edgar Allan Poe, seu grande maestro. Essa influência, deixemos claro, não diminui em nada a originalidade de Horacio Quiroga (1878-1937). O amor, a loucura e a morte - sobretudo nesses três contos - se entrelaçam de maneira única, tendo, como pano de fundo, paisagens que vão desde os arrabales da periferia de Buenos Aires até as zonas mais selvagens, como a fronteira entre Argentina, Brasil e Paraguai.

O elemento amor pode ser visto de forma mais intensa nos dois primeiros contos. A loucura se faz presente não só nos irmãos idiotas d'A Galinha Degolada, mas nos delírios envenenados do personagem de À Deriva, enquanto sua canoa ruma pelo Rio Paraná em direção ao Paraguai. E a morte que acompanha todos os contos, inexoravelmente.

Além do elemento morte, outro elemento importante - que subjaz este - é o espectro da noite. Quiroga explora magistralmente a diminuição da luminosidade e o pôr-do-sol como elemento que intensifica a tensão da narrativa no momento em que o espectro da morte se manifesta, ceifando a vida das personagens e levando-as para o más allá.

No mais, esperamos que as três traduções desses contos deem conta de transmitir um pouco do universo de Quiroga e que sua leitura seja tão deleitosa como o foi para mim ao traduzi-los.

\footnotetext{
${ }^{1}$ In Horacio Quiroga, Cuentos de amor de locura y de muerte, 2009, p. 9.
} 


\section{A Galinha Degolada}

O dia inteiro, sentados num banco do pátio, estavam os quatro filhos idiotas do casal Mazzini-Ferraz. Tinham a língua entre os lábios, os olhos estúpidos e viravam a cabeça com a boca aberta.

O pátio era de terra, fechado a oeste por um muro de tijolos. O banco ficava paralelo a ele, a cinco metros, e ali eles se mantinham imóveis, os olhos fixos nos tijolos. Como o sol se ocultava atrás do muro ao se pôr, os idiotas faziam festa. A luz ofuscante chamava sua atenção no início, pouco a pouco seus olhos se animavam; riam-se, por fim, estrepitosamente, congestionados pela mesma hilaridade ansiosa, olhando para o sol com alegria bestial, como se fosse comida.

Em outros momentos, alinhados no banco, zumbiam horas inteiras, imitando o bonde elétrico. Os fortes ruídos sacudiam também sua inércia, e se punham então a correr, mordendo-se a língua e mugindo ao redor do pátio. Mas quase sempre estavam apagados num sombrio letargo do idiotismo. Com as pernas pendentes e quietas, empapando de saliva viscosa as suas calças.

O mais velho tinha doze anos e o mais novo, oito. Em todo seu aspecto sujo e desvalido, era notável a falta absoluta de um pouco de cuidado maternal.

Esses quatro idiotas, entretanto, tinham sido um dia o encanto dos seus pais. Aos três meses de casados, Mazzini e Berta orientaram seu estreito amor de marido e mulher, e mulher e marido, para um porvir muito mais vital: um filho. Que maior alegria para dois apaixonados que essa honrada consagração de seu carinho, já libertado do vil egoísmo de um mútuo amor sem fim nenhum e, o que é pior para o próprio amor, sem esperanças possíveis de renovação?

Assim se sentiram Mazzini e Berta, e quando o filho chegou, aos catorze meses de matrimônio, acreditaram na completude de sua felicidade. A criança cresceu bela e radiante, até chegar a um ano e meio. Porém, no vigésimo mês, foi sacudida uma noite por convulsões terríveis, e na manhã seguinte já não 
reconhecia mais os seus pais. O médico examinou com essa atenção profissional que visivelmente busca as causas do mal nas enfermidades dos pais.

Depois de alguns dias, os membros paralisados recuperaram o movimento; mas a inteligência, a alma, até mesmo o instinto, tinham desaparecido totalmente; havia ficado profundamente idiota, babão, molenga, morto para sempre sobre os joelhos de sua mãe.

- Filho, meu filho querido! - soluçava ela sobre aquela espantosa ruína de seu primogênito.

O pai, desolado, acompanhou o médico à saída.

- Ao senhor, o que eu posso dizer: creio que é um caso perdido. Poderá melhorar, se educar em tudo o que lhe permita seu idiotismo, mas nada além disso.

- Sim!...Sim! - assentia Mazzini -. Mas me diga: O senhor acredita que é herança, que...?

- Quanto à herança paterna, já lhe disse o que achava quando vi o seu filho. Em relação à mãe, há aí um pulmão que não sopra bem. Não vejo mais nada, mas há um sopro um pouco áspero. Faça com que seja examinada minuciosamente.

Com a alma dilacerada de remorso, Mazzini redobrou o amor a seu filho, o pequeno idiota que pagava pelos excessos do avô. Teve também que consolar, apoiar constantemente a Berta, profundamente ferida por aquele fracasso de sua jovem maternidade.

Como é natural, o casal colocou todo o seu amor na esperança de outro filho. Ele nasceu, e sua saúde e limpidez de riso acenderam o porvir antes extinguido. Porém, aos dezoito meses, as convulsões do primogênito se repetiram, e no dia seguinte o segundo filho amanhecia idiota. 
Desta vez os pais caíram em profundo desespero. Pois, seu sangue, seu amor eram malditos! Seu amor, sobretudo! Vinte e oito anos ele, vinte e dois ela, e toda sua apaixonada ternura não alcançava para criar um átomo de vida normal. Já não pediam mais beleza e inteligência como no primogênito; mas um filho, um filho como todos!

Do novo desastre brotaram novas chamas do dolorido amor, um louco desejo de redimir de uma vez por todas a santidade de sua ternura. Desta vez vieram gêmeos, e ponto a ponto se repetiu o processo dos dois mais velhos.

Mas, acima de sua imensa amargura, permanecia em Mazzini e Berta uma grande compaixão pelos seus quatro filhos. Foi necessário arrancar do limbo da mais profunda animalidade, já não suas almas, mas o instinto mesmo, abolido. Não sabiam engolir, mudar de lugar, nem mesmo sentar-se. Aprenderam finalmente a caminhar, mas se batiam contra tudo, por não se darem conta dos obstáculos. Quando eram lavados, mugiam até que ficassem injetados de sangue no rosto. Alegravam-se só quando comiam, ou quando viam cores brilhantes ou ouviam trovões. Eles riam então, jogando para fora a língua e rios de baba, radiantes de frenesi bestial. Tinham, entretanto, certa faculdade imitativa; mas não foi possível obter nada mais.

Com os gêmeos parecia ter concluído a aterradora descendência. Mas, passados três anos, desejaram de novo ardentemente um outro filho, confiando que o longo tempo transcorrido tivesse aplacado a fatalidade.

Não satisfaziam suas esperanças. E nesse ardente anseio que se exasperava em razão de sua infrutuosidade, tornaram-se mais amargos. Até esse momento cada qual tinha tomado para si a parte que lhe correspondia na miséria de seus filhos; mas a desesperança de redenção diante das quatro bestas que tinham nascido deles provocou essa imperiosa necessidade de culpar os outros, que é patrimônio específico dos corações inferiores. 
Começaram pela troca de pronome: teus filhos. E como além do insulto havia a insídia, a atmosfera ficava carregada.

- Eu acho - disse-lhe uma noite Mazzini, que acabava de entrar e lavava suas mãos - que tu poderias manter mais limpos os meninos.

Berta continuou lendo como se não tivesse ouvido.

- É a primeira vez - respondeu em seguida - que te vejo preocupado pelo estado dos teus filhos.

Mazzini virou o rosto para ela com um sorriso forçado:

- De nossos filhos, quer dizer?

- Bom, dos nossos filhos. Melhor assim? - ela levantou os olhos.

Desta vez Mazzini se expressou claramente:

- Acredito que não vais dizer que eu tenha a culpa, não?

- Ah não! - Sorriu Berta, muito pálida. - Mas eu também não, suponho!... Era o que me faltava!... - murmurou.

- O que te faltava?

- Que se alguém tem a culpa, não sou eu, dá pra entender bem! Isso é que eu queria te dizer.

Seu marido a olhou por um momento, com brutal desejo de insultá-la.

- Vamos deixar assim! - disse, secando por fim as mãos.

- Como quiseres; mas se queres dizer...

- Berta!

- Como quiseres! 
Esse foi o primeiro choque e sucederam-lhe outros. Mas nas inevitáveis reconciliações, suas almas se uniam com o dobro de arrebatamento e loucura por outro filho.

Nasceu assim uma menina. Viveram dois anos com a angústia à flor da pele, esperando sempre outro desastre. Nada aconteceu, entretanto, e os pais puseram nela toda sua complacência, que a pequena levava aos mais extremos limites do mimo e da má criação.

Se ainda nos últimos tempos Berta cuidava sempre de seus filhos, ao nascer Bertita, esqueceu-se quase por completo dos outros. Sua mera lembrança a horrorizava, como algo atroz que a tivessem obrigado a cometer. Para Mazzini, ainda que em menor grau, acontecia o mesmo. Nem por isso a paz havia chegado às suas almas. A menor indisposição de sua filha aflorava, com o terror de perdêla, os rancores de sua descendência podre. Haviam acumulado fel a bastante tempo para que o copo não ficasse cheio e, ao menor contato o veneno, jorrasse para fora. Desde o primeiro desgosto peçonhento, tinham perdido o respeito; e se há algo pelo qual o homem se sente arrastado com cruel fruição é, depois de começar, terminar de humilhar uma pessoa por completo. Antes se continham pela mutua falta de sucesso; agora que o tinham alcançado, cada qual, atribuindoo a si mesmo, sentia maior a infâmia das quatro criaturas que o outro o havia forçado a engendrar.

Com estes sentimentos, não houve afeto possível para os quatro filhos maiores. A criada os vestia, dava de comer, punha-os na cama, com visível brutalidade. Não os lavavam quase nunca. Passavam todo o dia sentados de frente pro muro, abandonados pela mais remota carícia. Desta maneira, Bertita fez quatro anos e, nessa noite, resultado das guloseimas que era aos pais algo absolutamente impossível de negar-lhe, a criança teve algum calafrio e febre. E o temor de vê-la morrer ou ficar idiota, tornou a reabrir a eterna chaga.

Fazia três horas que não falavam, e o motivo foi, como quase sempre, os fortes passos de Mazzini. 
- Meus Deus! Não podes caminhar mais devagar? Quantas vezes...?

- Bom, é que eu me esqueço; deu! Não faço de propósito.

Ela sorriu, desdenhosa: - Não, não acredito muito em ti...

- Nem eu jamais teria acreditado em ti... tisicazinha!

- O quê! O que disseste?...

- Nada!

- Sim, falaste algo! Olha: eu não sei o que disseste; mas te juro que prefiro qualquer coisa do que ter um pai como o que tu tiveste!

Mazzini ficou pálido.

- Até que enfim! - murmurou com os dentes apertados - Até que enfim, víbora, falaste o que querias!

- Sim, víbora sim! Mas eu tive pais saudáveis, ouviste? Saudáveis! Meu pai não morreu de delírio! Eu teria filhos como os de todo mundo! Esses filhos são teus, os quatro teus!

Mazzini então explodiu.

- Víbora tísica! É isso o que eu te disse, o que eu quero te dizer! Pergunta ao médico quem tem a maior culpa da meningite dos teus filhos: meu pai ou teu pulmão furado, víbora!

Continuaram cada vez com maior violência, até que um gemido de Bertita selou instantaneamente suas bocas. À uma da manhã a leve indigestão tinha desaparecido, e como acontece fatalmente com todos os matrimônios jovens que se amaram intensamente ao menos uma vez, a reconciliação chegou, tão mais efusiva quanto foram infames os agravos. 
Amanheceu um esplêndido dia, e enquanto Berta se levantava, cuspiu sangue. As emoções e a má noite anterior tinham, sem dúvida, grande culpa. Mazzini a manteve abraçada por longo tempo, e ela chorou desesperadamente, mas sem que nenhum se atrevesse a dizer uma palavra.

Às dez decidiram sair, depois de almoçar. Como tinham pouco tempo, mandaram que a criada matasse uma galinha.

O dia radiante tinha arrancado os idiotas do seu banco. De maneira que, enquanto a criada degolava o animal na cozinha, sangrando-o calmamente (Berta tinha aprendido com sua mãe essa boa maneira de conservar o frescor da carne), sentiu que havia algo atrás dela. Virou-se e viu os quatro idiotas, com os ombros colados um no outro, olhando estupefatos a operação... Vermelho... vermelho...

- Senhora, os meninos estão aqui, na cozinha.

Berta chegou; não queria jamais que pisassem ali. E nem nessas horas de pleno perdão, esquecimento e felicidade reconquistada, podia evitar essa horrível visão! Porque, naturalmente, quanto mais intensos eram os raptos de amor para com seu marido e filha, mais irritado era seu humor com os monstros.

- Que saiam, Maria! Expulse-os! Expulse-os, lhe digo!

As quatro pobres bestas, sacudidas, brutalmente empurradas, foram parar no seu banco.

Depois de almoçar saíram todos. A criada foi a Buenos Aires e o matrimônio foi passear pelas chácaras vizinhas. Voltaram ao cair do sol; mas Berta quis cumprimentar por um tempo as suas vizinhas da frente. Sua filha se escapou em seguida para casa. 
Entretanto os idiotas não tinham saído durante todo o dia do seu banco. $\mathrm{O}$ sol tinha já ultrapassado o muro, começava a se pôr, e eles continuavam olhando os tijolos, mais inertes que nunca.

De repente algo se interpôs entre seu olhar e o muro. Sua irmã, cansada de cinco horas paternais, queria observar por conta própria. Parada ao pé do muro, olhava pensativa para a parte de cima. Queria subir, não havia dúvidas. No fim se decidiu por uma cadeira sem assento, mas ainda não alcançava. Recorreu então a um caixote de querosene, e seu instinto topográfico a fez colocá-lo na vertical, com o qual triunfou.

Os quatro idiotas, o olhar indiferente, viram como sua irmã conseguia pacientemente dominar o equilíbrio e como, nas pontas dos pés, apoiava a garganta sobre o topo do muro, entre suas mãos esticadas. Viram-na olhar para todos os lados, e buscar apoio com o pé para subir mais.

Mas o olhar dos idiotas havia se animado; uma mesma luz insistente estava fixa em suas pupilas. Não tiravam os olhos de sua irmã enquanto uma crescente sensação de gula bestial ia transformando cada linha de seus rostos. Lentamente avançaram sobre o muro. A pequena, que já tinha conseguido calçar o pé, já estava por montar no muro e cair certamente para o outro lado, sentiu que lhe agarraram pela perna. Debaixo dela, os oito olhos cravados nos seus the deram medo.

- Me solta! Me deixa! - gritou sacudindo a perna. Mas foi agarrada.

- Mamãe! Ai, mamãe! Mamãe, papai! - chorou imperiosamente. Tentou ainda se agarrar na borda, mas foi arrancada e caiu.

- Mamãe, ai! Ma... - Não pôde mais gritar. Um deles apertou-lhe o pescoço, afastando os cachos como se fossem penas, e os outros a arrastaram por uma só perna até a cozinha, onde nessa manhã tinham sangrado a galinha, bem agarrada, arrancando-lhe a vida segundo a segundo. 
Mazzini, na casa da frente, achou ter ouvido a voz de sua filha.

- Acho que está te chamando - disse à Berta.

Prestaram atenção, inquietos, mas não ouviram mais. Mesmo assim, um momento depois se despediram, e enquanto Berta ia guardar seu chapéu, Mazzini avançou até o pátio.

- Bertita!

- Ninguém respondeu.

- Bertita! - Aumentou mais a voz, já alterada.

E o silêncio foi tão fúnebre para seu coração tão aterrorizado, que suas costas congelaram de um horrível pressentimento.

- Minha filha, minha filha! - correu já desesperado para o fundo. Mas ao passar diante da cozinha, viu no chão um mar de sangue. Empurrou violentamente a porta entreaberta, e lançou um grito de horror.

Berta, que também já havia se lançado correndo ao ouvir o angustiante chamado do pai, ouviu o grito e respondeu com outro. Mas ao precipitar-se na cozinha, Mazzini, lívido como a morte, se interpôs, contendo-a:

- Não entres! Não entres!

Berta chegou a ver o chão inundado de sangue. Só conseguiu levar os braços à cabeça e jogar-se em cima dele, com um áspero suspiro. 


\section{O Travesseiro de Penas}

Sua lua de mel foi um longo calafrio. Loira, angelical e tímida, o forte temperamento de seu marido congelou as suas sonhadas fantasias de noiva. Ela o adorava muito, entretanto, às vezes com um ligeiro estremecimento quando, ao voltarem de noite juntos pela rua, ela dava uma furtiva olhada para a alta estatura de Jordán, mudo já fazia uma hora. Ele, por sua vez, a amava profundamente, sem que ela percebesse.

Durante três meses - tinha se casado em abril - viveram uma especial alegria.

Sem dúvidas teria ela desejado menos severidade neste rígido céu de amor, uma ternura mais expansiva e incauta; mas o impassível semblante de seu marido sempre a continha.

A casa em que viviam influenciava um pouco em seus estremecimentos. A brancura do pátio silencioso - frisos, colunas e estátuas de mármore - produzia uma impressão outonal de palácio encantado. Dentro, o brilho glacial do estuque, sequer havia o mais leve arranhão nas altas paredes, confirmava aquela sensação de incômodo frio. Ao cruzar de uma peça a outra, os passos ecoavam em toda a casa, como se um longo abandono houvesse sensibilizado sua ressonância.

Neste estranho ninho de amor, Alícia passou todo o outono. Não obstante, decidiu por colocar um véu sobre seus antigos sonhos, e vivia como adormecida na casa hostil, sem querer pensar em nada até que chegasse o seu marido.

Não se estranha que tenha emagrecido. Teve um ligeiro ataque de gripe que se arrastou insidiosamente por vários dias; Alícia não se recuperava nunca. Por fim pôde sair uma tarde ao jardim apoiada no braço dele. Olhava indiferente para os lados. De repente Jordán, com grande ternura, passou a mão por sua cabeça, e logo Alícia irrompeu em soluços, colocando seus braços no pescoço dele. Chorou longamente todo seu espanto calado, aumentando o pranto a qualquer 
tentativa de carícia. Logo os soluços foram diminuindo, e ficou ainda por longo tempo escondida em seu pescoço, sem se mover nem dizer uma palavra.

Esse foi o último dia que Alícia esteve levantada. No dia seguinte amanheceu desvanecida. O médico de Jordán a examinou com suma atenção, pedindo-lhe calma e descanso absolutos.

- Não sei - disse a Jordán na porta da frente, com a voz ainda baixa - ela tem uma grande fraqueza que não se explica, e sem vômitos, nada... Se amanhã ela se levantar como hoje me chame em seguida.

No outro dia Alícia continuava pior. Foi examinada. Constatou-se uma anemia agudíssima, completamente inexplicável. Alícia não teve mais desmaios, mas estava visivelmente indo em direção à morte. $O$ quarto estava com as luzes acesas durante todo o dia e em pleno silêncio. Passavam as horas sem que se ouvisse o menor ruído. Alícia cochilava. Jordán quase vivia na sala, também com a luz toda acesa. Caminhava sem cessar de um extremo a outro, com incansável obstinação. $\mathrm{O}$ tapete amortecia seus passos. A cada tanto entrava no dormitório e prosseguia seu mudo vaivém ao redor da cama, olhando sua mulher cada vez que caminhava em sua direção.

Em pouco tempo Alícia começou a ter alucinações, confusas e flutuantes no início, e que logo descenderam ao chão. A jovem, com os olhos desmesuradamente abertos, olhava apenas para o tapete de um lado a outro da cama. Uma noite, de repente, permaneceu olhando fixamente. Logo depois abriu a boca para gritar, e seu nariz e lábios encheram-se de suor.

- Jordán! Jordán! - gritou, rígida de espanto, sem deixar de olhar para o tapete.

Jordán correu para o quarto, e ao vê-lo se aproximar Alícia deu um grito de horror. 
- Sou eu, Alícia, sou eu!

Alícia o olhou perdidamente, olhou para o tapete, voltou a olhá-lo, e depois de um longo tempo de estupefata confrontação, se acalmou. Sorriu e tomou entre as suas a mão de seu marido, acariciando-a tremendo.

Entre suas alucinações mais persistentes, houve um antropoide, apoiado no tapete sobre os dedos, que tinha os olhos fixos nela.

Os médicos retornaram inutilmente. Havia ali diante deles uma vida que se acabava, definhando dia a dia, hora a hora, sem que se soubesse absolutamente como. Na última consulta Alícia jazia num estupor enquanto eles tomavam-lhe o pulso, passando de um a outro o punho inerte. Observaram-na por longo tempo em silêncio e foram para a sala de estar.

- Pst... - seu médico encolheu os ombros desanimado. É um caso sério... não há muito o que fazer...

- Só me faltava essa! - suspirou Jordán. E tamborilou bruscamente sobre a mesa.

Alícia foi se extinguindo no seu delírio de anemia, que piorava à tarde, mas que sempre diminuía nas primeiras horas. Durante o dia a sua doença não avançava, mas a cada manhã ela amanhecia lívida, quase em síncope. Parecia que unicamente de noite a vida lhe escapava em novas ondas de sangue. Tinha sempre ao acordar a sensação de estar jogada na cama com um milhão de quilos em cima. Desde o terceiro dia este abatimento não a abandonou mais. Apenas podia mover a cabeça. Não quis que mexessem na cama, nem mesmo que lhe ajeitassem o travesseiro. Seus terrores crepusculares avançaram em forma de monstros que se arrastavam até a cama e trepavam dificultosamente pela colcha.

Logo perdeu a consciência. Os dois dias finais delirou sem cessar em voz baixa. As luzes continuavam funebremente acendidas no dormitório e na sala. 
No silêncio agonizante da casa, apenas se ouvia o delírio monótono que saía da cama, e o rumor abatido dos eternos passos de Jordán.

Alícia morreu, por fim. A criada, que entrou depois para arrumar a cama, já sozinha, olhou por um instante com estranheza ao travesseiro.

- Senhor! - chamou Jordán em voz baixa. Há manchas no travesseiro que parecem sangue.

Jordán aproximou-se rapidamente e se curvou sobre ele. De fato, sobre a fronha em ambos os lados do buraco que havia deixado a cabeça de Alícia, via-se pequenas manchas escuras.

- Parecem picadas - murmurou a criada depois de um instante de imóvel observação.

- Erga-o na luz - Disse-lhe Jordán.

A criada o levantou, mas logo o deixou cair, e ficou olhando aquilo, lívida e tremendo. Sem saber por quê, Jordán sentiu que seus cabelos se eriçavam.

- Que tem aí? - murmurou com a voz roca.

- Pesa muito - articulou a empregada, sem deixar de tremer.

Jordán levantou o travesseiro; pesava extraordinariamente. Saíram com ele, e sobre a mesa da sala Jordán cortou fronha e envoltório num só corte. As penas superiores voaram, e a criada deu um grito de horror com toda a boca aberta, levando as mãos crispadas aos cabelos. No fundo, entre as penas, movendo lentamente as patas peludas, havia um animal monstruoso, uma bola viva e viscosa. Estava tão inchado que mal conseguia abrir a boca.

Noite após noite, desde que Alícia tinha ficado de cama, ele havia aplicado sigilosamente sua boca - sua trompa, melhor dizendo - nas têmporas da mulher, sugando o seu sangue. A picada era quase imperceptível. A remoção diária do 
travesseiro havia sem dúvidas impedido o seu desenvolvimento, mas desde que a jovem não conseguiu mais se mover, a sucção foi vertiginosa. Em cinco dias, em cinco noites havia esvaziado Alícia.

Estes parasitas das aves, diminutos no meio habitual, chegam a adquirir proporções enormes em certas condições. $O$ sangue humano parece ser-lhes particularmente favorável, e não é raro encontrá-los em travesseiros de pena. 


\section{À Deriva}

O homem pisou em algo meio mole e em seguida sentiu uma picada no pé. Deu um salto para frente, e ao virar-se com um xingamento, viu uma jararacuçu que, enrolada sobre si mesma, esperava outro ataque.

O homem deu uma rápida olhada no seu pé, onde duas pequenas gotas de sangue engrossavam dificultosamente, e tirou um facão da cintura. A víbora viu a ameaça e afundou mais a cabeça no centro de sua própria espiral; mas o facão acertou-lhe o lombo, deslocando suas vértebras.

O homem se agachou até a mordida, tirou as pequenas gotas de sangue e durante um instante contemplou. Uma dor aguda nascia dos dois pontinhos roxos, e começava a invadir todo o pé. Apressadamente atou o tornozelo com seu lenço e seguiu pela trilha até o seu rancho.

A dor no pé aumentava, com sensação de um grande inchaço, e logo o homem sentiu duas ou três fulgurantes pontadas que, como relâmpagos, irradiavam da ferida até a metade da panturrilha. Movia a perna com dificuldade; uma metálica secura na garganta, seguida de uma sede queimante, arrancou-lhe outro xingamento.

Chegou finalmente no rancho e se jogou de braços sobre a roda de um moinho. Os dois pontinhos roxos desapareceriam agora e o monstruoso inchaço do pé inteiro. A pele parecia mais fina a ponto de ceder, de tão tensa. Ele quis chamar sua mulher e a voz travou-lhe num arrastar rouco de garganta ressecada. A sede o devorava.

- Dorotea! - conseguiu articular em meio à agonia. - Me dá canha!

Sua mulher correu com um copo cheio, que o homem tomou em três goles. Porém não havia sentido gosto algum.

- Te pedi canha, não água! - rugiu de novo. - Me dá canha! 
- Mas é canha, Paulino! - protestou a mulher, espantada.

- Não, me trouxeste água! Quero canha, estou te dizendo!

A mulher correu outra vez, voltando com a garrafa. O homem tomou dois copos, um atrás do outro, mas não sentiu nada na garganta.

Bem; isto está ficando feio - murmurou então, olhando seu pé lívido e com um brilho gangrenoso. Sobre a funda atadura do lenço, a carne transbordava como uma monstruosa morcilha.

As dores fulgurantes aconteciam em contínuos relâmpagos e estavam chegando à virilha. A atroz secura da garganta que a respiração parecia aquecer, aumentava cada vez mais. Quando tentou levantar, um fulminante vômito o manteve meio minuto com a testa apoiada na roda da madeira.

Mas o homem não queria morrer, e descendo até a margem, subiu na sua canoa. Sentou-se na popa e começou a remar até o centro do Paraná. Ali, a corrente do rio, que nas imediações do Iguaçu corre a seis milhas, o levaria antes das cinco horas a Tacuru-Pucu.

O homem, com sombria energia, pôde efetivamente chegar até o meio do rio; mas ali, suas mãos dormentes deixaram cair o remo na canoa, e depois de um novo vômito - de sangue dessa vez - observou o sol, que já ultrapassava o monte.

A perna inteira, até meia coxa, já era um bloco desforme e duríssimo que arrebentava a roupa. $\mathrm{O}$ homem cortou a atadura e abriu a calça com sua faca: $\mathrm{o}$ baixo ventre transbordou inchado, com grandes manchas lívidas e terrivelmente doloroso. $\mathrm{O}$ homem pensou que não poderia jamais chegar sozinho a Tacuru-Pucu, e decidiu pedir ajuda a seu compadre Alves, ainda que fizesse muito tempo que eles não se davam mais. 
A corrente do rio se precipitava agora em direção à margem brasileira, e o homem pôde facilmente atracar. Arrastou-se pela trilha ladeira acima, mas, aos vinte metros, exausto, ficou estendido de bruços.

- Alves! - gritou com toda maior força possível; e prestou atenção em vão. - Compadre Alves! Não me negue esse favor! - clamou novamente, levantando a cabeça do chão. No silêncio da selva não se ouviu um rumor sequer. O homem teve ainda forças para voltar até sua canoa, e a corrente, agarrando-a de novo, levou-a velozmente à deriva.

O Paraná corre ali no fundo de uma imensa bacia, cujas paredes, altas de cem metros, estreitam funebremente o rio. Das orlas bordeadas de negros blocos de basalto, ergue-se o bosque, negro também. Adiante, nos lados, atrás, a eterna muralha lúgubre, em cujo fundo o rio em remoinho se precipita em incessantes borbotões de água lodosa. A paisagem é agressiva, e reina nela um silêncio de morte. Ao entardecer, entretanto, sua beleza sombria e calma adquire uma majestade única.

O sol já havia se posto quando o homem, semi-estendido no fundo da canoa, teve um violento calafrio. E em seguida, surpreso, ergueu pesadamente a cabeça: se sentia melhor. A perna mal doía, a sede diminuía, e seu peito, já livre, se abria em lenta inspiração.

O veneno começava a ir embora, não havia dúvidas. Encontrava-se quase bem, e mesmo que não tivesse forças para mover a mão, contava com a queda do orvalho para recuperar-se totalmente. Calculou que em menos de três horas estaria em Tacuru-Pucu.

O bem-estar avançava, e com ele uma sonolência cheia de recordações. Já não sentia nada nem na perna nem no ventre. Seu compadre Gaona moraria ainda em Tacuru-Pucu? Caso visse também o seu ex-patrão mister Dougald e o estoquista da madeireira. 
Chegaria logo? O céu, ao poente, se abria agora numa tela de ouro e o rio estava colorido também. Da margem paraguaia, já escurecida, o monte deixava cair sobre o rio seu frescor crepuscular, em penetrantes eflúvios de laranjeira e mel silvestre. Um casal de araras cruzou bem alto e em silêncio até o Paraguai.

Lá embaixo, sobre o rio de ouro, a canoa avançava velozmente, girando a cada tanto sobre si mesma diante do borbotão de um remoinho. O homem que ia nela se sentia cada vez melhor, e enquanto isso pensava no tempo que havia passado sem ver o seu ex-patrão Dougald. Três anos? Talvez não, não tanto. Dois anos e nove meses? Talvez. Oito meses e meio? Isso sim, certamente.

De repente sentiu que estava gelado até o peito.

O que seria? E a respiração...

O estoquista de madeiras do mister Dougald, Lorenzo Cubilla, eu o conheci em Puerto Esperanza numa sexta-feira santa... sexta? Sim, ou quinta...

O homem esticou lentamente os dedos da mão.

- Numa quinta...

E parou de respirar. 


\section{Referência}

QUIROGA, Horacio. Cuentos de amor de locura y de muerte. Flor Negra Ediciones, Montevideo: 2009.

Referência para citação desta tradução ACOSTA, Juan. Três contos de morte de Horacio Quiroga. Revista PHILIA | Filosofia, Literatura \& Arte, Porto Alegre, volume 1, número 2, p. 575 - 595, outubro de 2019. 